Archived version from NCDOCKS Institutional Repository http://libres.uncg.edu/ir/asu/

\title{
Appalachỉan
}

B O O N E, N O R T H C A R O L I N A

\section{Mating In The Presence Of A Competitor: Audience Effects May Promote Male Social Tolerance In Polyandrous Siamang (Symphalangus syndactylus) Groups}

\author{
By: Susan Lappan and L. Morino
}

\begin{abstract}
Audience effects on sexual behavior, including changes in copulation frequency and duration in the presence of conspecifics, have been reported in multimale - multifemale groups of several primate species. We examined the interaction of male sexual behavior with group composition and within-group mating pattern in a population of siamangs (Symphalangus syndactylus) containing unimale - unifemale groups and multimale - unifemale groups using mixed models. Aggression in a sexual context was never observed. As predicted, however, copulation rates were lower and copulations were significantly shorter in duration in two-male groups than in unimale groups, even if copulations involving subordinate males were excluded. Dominant males monopolized copulations with the group female in most groups, but copulations were shared among males in three stable two-male groups. When both resident males copulated with the group's female, there was no evidence that copulating pairs moved to secluded areas, and the duration of copulations did not differ between males. These results are consistent with the hypothesis that male - male tolerance in multimale siamang groups is facilitated by adjustments to sexual behavior in the presence of a sexual competitor.
\end{abstract}

Lappan, S., \& Morino, L. (2014). Mating in the presence of a competitor: audience effects may promote male social tolerance in polyandrous siamang (Symphalangus syndactylus) groups, Behaviour, 151 (7), 1067-1089. doi: https://doi.org/10.1 163/1568539X-00003170. Publisher version of record available at: https://brill.com/ view/journals/beh/151/7/article-p1067_9.xml 


\title{
Mating in the presence of a competitor: audience effects may promote male social tolerance in polyandrous siamang (Symphalangus syndactylus) groups
}

\author{
S. Lappan ${ }^{\mathrm{a}, *}$ and L. Morino ${ }^{\mathrm{b}, \mathrm{c}}$ \\ ${ }^{a}$ Department of Anthropology, Appalachian State University, Boone, NC 28608, USA \\ ${ }^{\mathrm{b}}$ Primate Research Institute, Kyoto University, Inuyama, Aichi 484-8506, Japan \\ ${ }^{c}$ Department of Anthropology, Rutgers University, Ruth Adams Building, \\ 131 George Street, New Brunswick, NJ 08901-1414, USA \\ *Corresponding author's e-mail address: lappansm@appstate.edu
}

Accepted 17 December 2013; published online 22 January 2014

\begin{abstract}
Audience effects on sexual behavior, including changes in copulation frequency and duration in the presence of conspecifics, have been reported in multimale-multifemale groups of several primate species. We examined the interaction of male sexual behavior with group composition and within-group mating pattern in a population of siamangs (Symphalangus syndactylus) containing unimale-unifemale groups and multimale-unifemale groups using mixed models. Aggression in a sexual context was never observed. As predicted, however, copulation rates were lower and copulations were significantly shorter in duration in two-male groups than in unimale groups, even if copulations involving subordinate males were excluded. Dominant males monopolized copulations with the group female in most groups, but copulations were shared among males in three stable two-male groups. When both resident males copulated with the group's female, there was no evidence that copulating pairs moved to secluded areas, and the duration of copulations did not differ between males. These results are consistent with the hypothesis that male-male tolerance in multimale siamang groups is facilitated by adjustments to sexual behavior in the presence of a sexual competitor.
\end{abstract}

\section{Keywords}

audience effects, Way Canguk, sexual behavior, copulation duration, copulation frequency, mating systems, monogamy, polyandry. 


\section{Introduction}

For males living in multimale animal groups, other male group members are often important competitors for resources and paternity of group offspring. When an individual can economically exclude group members from valuable resources or fertilizations, competition should occur via aggressive contests and dominance hierarchies will form (Nicholson, 1954). Accordingly, males of a variety of species routinely direct aggression at other male group members, especially in a sexual context (e.g., baboons (Papio cynocephalus): Alberts et al., 1996; stumptailed macaques (Macaca arctoides), Bruce \& Estep, 1992; rhesus macaques (Macaca mulatta): Chapais, 1983; Manson, 1996; Overduin-de Vries et al., 2012; chimpanzees (Pan troglodytes): Watts, 1998; bonobos (Pan paniscus): Hohmann \& Fruth, 2003; horses (Equus caballus): Linklater \& Cameron, 2000; alpine accentors (Prunella collaris): Nakamura, 1998; acorn woodpeckers (Melanerpes formicivorus); Mumme et al., 1983). Dominant males may attempt to monopolize copulations by mate-guarding (Parker, 1974) or by aggressively interrupting copulations or copulation attempts by other males (Manson, 1994). These strategies lead to pronounced reproductive skew in some animal societies, with dominant males monopolizing all or most paternity within a group (reviewed in Clutton-Brock, 1998). Aggression can occur in multimale groups with low or high reproductive skew (Cant \& Johnstone, 2000), but tension among males is expected to be highest when subordinate males are competitors for fertilizations. Aggression can impose high costs on actors and recipients, including time and energy costs (Marler \& Moore, 1989), the costs of physiological changes associated with aggressive competition (Sapolsky, 2005), and the risk or injury or death (Kaburu et al., 2013). Animals in multimale groups may therefore benefit from behavioral mechanisms that minimize the risk of aggression.

Where the outcomes of contests are predictable, and losing is costly, subordinate individuals should avoid behaviors likely to provoke aggression by dominants. Changes in behavior in the presence of conspecifics, or audience effects, have been reported in many animal species (Matos \& Schlupp, 2005), and audience effects in a sexual context are particularly well-documented. Individuals of many species adjust their signaling to deceive observers about the actor's sexual interest in a specific partner. For example, males of several live-bearing fish species (Poeciliidae) reduce their rates of copulation solicitation in the presence of same-sex conspecifics, which has been interpreted 
as a tactic to avoid revealing information about mate preferences (Padur et al., 2009). Similarly, zebra finches (Taeniopygia guttata) signal greater sexual interest in less-preferred females in the presence of other males than in their absence (Dubois \& Belzile, 2012). Audience effects may also function to conceal copulations with or by low-ranking individuals. Female chimpanzees (Pan troglodytes) produce copulation calls at higher rates when copulating with high-ranking males than low-ranking males, but refrain from calling if higher-ranking females are nearby (Townsend et al., 2008). Similarly, female bonobos produce copulation calls at higher rates during genitalgenital contact with higher ranking female partners (Clay \& Zuberbühler, 2012). Copulation rates by subordinate males are lower in the presence of dominant males in domesticated rams (Ovis aries, Lindsay et al., 1976) and rhesus macaques (Overduin-de Vries et al., 2012). In rhesus macaques, females solicit copulations from non-alpha males at lower rates in the presence of other males (whether alpha or non-alpha) than in the absence of male observers, but female solicitations directed at alpha males occurred at the same rate in the presence or absence of observers (Overduin-de Vries et al., 2012). Copulating pairs of several primate species tend to move to secluded areas prior to copulation (e.g., spider monkeys (Ateles geoffroyi): Campbell, 2006; chimpanzees: Matsumoto-Oda, 1999), and subordinate male rhesus macaques have mount series of shorter duration than dominant males, presumably to minimize the risk of interruption (Manson, 1996).

Siamangs (Symphalangus syndactylus: Hylobatidae) are often reported to live in unimale-unifemale (socially monogamous) groups (Chivers, 1974; Palombit, 1994), but at the Way Canguk Research Station in southern Sumatra, Indonesia, approx. 25\% of groups contain two adult males (Lappan, 2007a, b; O'Brien \& Kinnaird, unpubl. data). Intolerance among adult males is thought to be among the most important factors promoting and maintaining social monogamy in mammals (Morino, 2009), including hylobatids (i.e., gibbons; Mitani, 1984, 1987; Raemaekers \& Raemaekers, 1985). However, we have not observed a dominant male attempt to evict a subordinate male in approx. 15 group-years of observations of multimale siamang groups. In contrast, two of the four subadult females observed in this study were aggressively evicted from their groups by their social mothers (Lappan, 2005), and groups containing two adult-sized females are very rare at Way Canguk (O’Brien \& Kinnaird, unpubl. data). Rates of intragroup aggression in 
two-male groups are very low in the Way Canguk siamang population (Lappan, 2007b; Morino, 2012), and male-male aggression in a sexual context in multimale groups has not been observed in $>5000 \mathrm{~h}$ of behavioral observations (Lappan, 2007b, unpubl. data; Morino, 2012). Male-male dyads in two-male siamang groups also regularly display affiliative interactions (Lappan, 2007b). These observations indicate some plasticity in siamang behavior with regard to male social relationships, grouping patterns and mating patterns. Peaceful coexistence can be mediated through avoidance of dominant individuals by subordinates, but siamang groups in this population are spatially cohesive, with both males spending $>50 \%$ of active time $\leqslant 20 \mathrm{~m}$ from other group adults (Lappan, 2007b; Morino, 2012). Males in multimale siamang groups at Way Canguk are therefore best described as socially tolerant of each other, but the mechanisms by which males avoid intra-group aggression have yet to be adequately explored.

There is a clear dominance hierarchy in most multimale siamang groups at Way Canguk (Morino, 2012). Dominant males monopolize copulations in some groups (Morino, 2012), but in other groups, both dominant and subordinate males copulate without receiving aggression (Lappan, 2007a). In one case, a siamang male was observed to return to a group in which he had previously resided as a subordinate and evict and replace the dominant male (Morino, 2012). These observations suggest that in at least some cases, subordinate siamangs are important competitors for paternity and breeding positions. The social tolerance observed in multimale siamang groups is surprising, therefore, and suggests the existence of effective behavioral mechanisms to mitigate the risk of within-group intra-sexual aggression in this population. Lethal aggression has been reported in hylobatids (Palombit, 1993), which indicates that the potential costs of male-male aggression are high. In spatially cohesive multimale groups, therefore, males, and particularly subordinate males, may benefit from strategies that reduce time and energy loss due to interrupted copulations and, more importantly, reduce their risk of provoking aggression (Townsend \& Zuberbuhler, 2009; Overduin-de Vries et al., 2012). Flexible behavioral mechanisms such as audience effects may be effective means by which siamangs achieve social harmony in the context of variable group structures.

In this study, we examine sexual behavior in unimale and multimale siamang groups to determine whether siamangs alter their behavior in the 
presence of a presumed sexual competitor. Specifically, we made three predictions: (1) Males in two-male groups have lower copulation rates than males in unimale groups; (2) copulations by males in two-male groups are of shorter duration than those by males in unimale groups; and (3) copulations by males in two-male groups, especially subordinate males, occur more frequently when the uninvolved male is out of visual range of the copulating pair.

\section{Methods}

\subsection{Research area}

This study was conducted at the Way Canguk Research Area in the southern part of the Bukit Barisan Selatan National Park (Taman Nasional Bukit Barisan Selatan, TNBBS) in southern Sumatra, Indonesia $\left(5^{\circ} 39^{\prime} 32^{\prime \prime} \mathrm{S}\right.$, $\left.104^{\circ} 24^{\prime} 21^{\prime \prime} \mathrm{E}\right)$. The $10 \mathrm{~km}^{2}$ research area is run jointly by the Wildlife Conservation Society-Indonesia Program (WCS-IP) and the TNBBS. Habitat within the research area consists mostly of primary forest embedded in a mosaic of forest damaged by fires, drought, selective logging, wind and earthquakes (Kinnaird \& O'Brien, 1998). The research area contains all or part of the home ranges of about 37 siamang groups (O'Brien et al., 2003). Research on siamang behavior and demography has been conducted in the area since 1999 by WCS-IP, undergraduate and graduate students and several foreign researchers (e.g., Nurcahyo, 1999; O'Brien et al., 2003; Lappan, 2007a, b; Morino, 2012; Elder, 2013).

\subsection{Study groups}

We used behavioral data collected during two time periods: SL collected data from five siamang groups between October 2000 and August 2002, and LM collected data from 11 groups from August 2007 to April 2009 (Table 1). Adult males were defined as individuals of full adult body size and build, without regard to their sexual or social behavior. Parous and non-parous female siamangs can be distinguished by the presence of a clinging infant, elongation of the nipples in parous females, or both, and each study group contained one and only one parous female. Parous females were described as adult and additional adult-sized females without infants or elongated nipples living in groups with parous females were described as subadult. All study individuals were fully habituated to human observers prior to the initiation 
Table 1.

Group name, type, and sampling duration in each sampling period.

\begin{tabular}{|c|c|c|c|}
\hline Sampling period & Group & Group type & Months \\
\hline \multirow[t]{8}{*}{ 2000-2002 } & A & $2 \mathrm{M}$ & Oct 2000-Dec 2001 \\
\hline & & $1 \mathrm{M}$ & Dec 2001-Aug 2002 \\
\hline & B & $2 \mathrm{M}$ & Oct 2000-Aug 2002 \\
\hline & $\mathrm{C}$ & $3 \mathrm{M}$ & Oct $2000-$ Dec 2000 \\
\hline & & $2 \mathrm{M}$ & Dec 2000-Feb 2002 \\
\hline & & $1 \mathrm{M}$ & Feb 2002-Aug 2002 \\
\hline & $\mathrm{F}$ & $2 \mathrm{M}$ & Jan 2001-Aug 2002 \\
\hline & G & $1 \mathrm{M}$ & May 2001-Aug 2002 \\
\hline \multirow[t]{16}{*}{ 2007-2009 } & A2 & $2 \mathrm{M}$ & Oct 2007-Apr 2009 \\
\hline & B2 & $2 \mathrm{M}$ & Sept 2007-Jul 2008 \\
\hline & & $1 \mathrm{M}$ & Jul 2008-Jan 2009 \\
\hline & & $\mathrm{U} 3 \mathrm{M}$ & Jan 2009-Mar 2009 \\
\hline & & $1 \mathrm{M}$ & Mar 2009-Apr 2009 \\
\hline & $\mathrm{C} 2$ & $2 \mathrm{M}$ & Sept 2009-Dec 2007 \\
\hline & & $1 \mathrm{M}$ & Dec 2007-Apr 2009 \\
\hline & $\mathrm{E}$ & $2 \mathrm{M}$ & Sept 2007-Apr 2009 \\
\hline & $\mathrm{F} 2$ & $2 \mathrm{M}$ & Oct 2007-Apr 2009 \\
\hline & G2 & $1 \mathrm{M}$ & Feb 2008-Apr 2009 \\
\hline & $\mathrm{H}$ & $2 \mathrm{M}$ & Feb 2008-Apr 2009 \\
\hline & $\mathrm{L}$ & $1 \mathrm{M}$ & Jan 2008-Mar 2009 \\
\hline & M & $2 \mathrm{M}$ & Oct 2007-Feb 2009 \\
\hline & $\mathrm{S}$ & $1 \mathrm{M}$ & Oct 2007-Mar 2009 \\
\hline & $\mathrm{U}$ & $2 \mathrm{M}$ & Sept 2007-Mar 2008 \\
\hline & & $1 \mathrm{M}$ & Mar 2008-Mar 2009 \\
\hline
\end{tabular}

For groups that were sampled during both the 2000-2002 and the 2007-2009 sampling periods $(\mathrm{A}-\mathrm{C}, \mathrm{F}$ and $\mathrm{G})$, the number 2 is appended to group names during the second sampling period (thus, for example, the group identified as A in 2000-2002 is identified as A2 in 20072009). $1 \mathrm{M}=$ group containing one adult male. $2 \mathrm{M}=$ group containing two adult males. $3 \mathrm{M}=$ stable grouping with three males. $\mathrm{U} 3 \mathrm{M}=$ unstable grouping with three males.

of data collection, and did not display any behaviors that suggested fear or avoidance of humans. Groups were identified as multimale during periods when they contained two or more adult males and unimale when they contained a single male. In multimale siamang groups at Way Canguk, one male is usually socially subordinate (Morino, 2012), but all adult males in a group generally spend $>50 \%$ of their time $\leqslant 20 \mathrm{~m}$ from each other and from the adult female (Lappan, 2007b). 
Male social tolerance may be favored by kin selection (Silk, 2002), and inbreeding avoidance may reduce mating competition in cases where one male is the biological offspring of the group female. Actual genetic relationships within the study groups are unknown, but some inferences can be drawn from mitochondrial DNA (mtDNA) sequences that are available from adults in the four two-male groups observed in 2000-2002 (Lappan, 2007a). In three groups (A, B and C), each adult had a different mtDNA haplotype, indicating that the female was not the mother or maternal sibling of either male, and that the males were also not maternal siblings (Lappan, 2007a). In the fourth multimale group (F), one adult male haplotype was identical to that of the adult female, so the possibility of a mother-son relationship could not be excluded (Lappan, 2007a). Genetic data are not yet available from the additional individuals observed in 2007-2009. Longitudinal group composition data suggest that at least two multimale groups included in this study formed from the retention of an adult pair's social (but not necessarily genetic) offspring (Morino, 2012).

All groups sampled in 2000-2002 were also sampled in 2007-2009. However, at least one member of each group dispersed between 2000 and 2007, and the identity of the dominant males in groups B and $\mathrm{G}$ changed between sampling periods or early in the second sampling period. Groups A, B, and $\mathrm{C}$ also contained subordinate adult males in 2007 that had been absent or immature in 2000-2002. Groups that were sampled in 2007-2009 are indicated by the addition of a 2 to the group name in the second sampling period (e.g., the group designated as group $\mathrm{G}$ in the 2000-2002 sampling period is designated as group G2 in the 2007-2009 sampling period; Table 1). All study groups contained one or two adult males throughout the study, except group C, which at the start of data collection in 2000 contained three males (Table 1), and group B, which went through a period of instability from December 2008 to March 2009 during a group takeover in which three males competed for the resident position in the group (Table 1; Morino, 2012). The third male in group $\mathrm{C}$ emigrated in the first months of the study, before the group $\mathrm{C}$ female was observed to copulate. Therefore, all copulations recorded in group $\mathrm{C}$ were in the unimale or two-male condition. Five groups transitioned from multimale to unimale during the course of a sampling period, and the second male was not observed during the last two months of the sampling period in a sixth group, and thus may have also dispersed. Copulations were not observed during the months where this group's status was unclear. 


\subsection{Copulation data collection}

SL and three field assistants collected behavioral data from five groups of siamangs between October 2000 and August 2002. Groups were systematically observed during all-day follows for five continuous days per month where possible and focal groups were selected on a rotating basis. Sexual interactions were recorded using all-occurrence sampling (Altmann, 1974), including the time, the identities of the participants, the duration of the copulation (in s) and any additional observations (e.g., harassment by others, evidence of ejaculation, etc.). The estimated distance (in $\mathrm{m}$ ) from the copulating pair to the second male in two-male groups was recorded when the location of the second male was known. SL collected $3076 \mathrm{~h}$ of behavioral data from focal adults. Each group was also contacted for 1-3 h/day during 30-40 additional days distributed throughout the 2001-2002 sampling period. Copulations occurring during all contact hours are included in these analyses. All individuals were recognizable based on their facial and body features, and were well known by the observers.

LM and five field assistants collected behavioral data from 11 siamang groups between August 2007 and April 2009. Groups were observed during all-day follows for 3-4 consecutive days each month, resulting in a total of approx. $4100 \mathrm{~h}$ of data. A different focal individual was selected each hour, and copulations involving the focal animal were recorded using all-occurrence sampling (Altmann, 1974), including the identity of the copulation partner and the duration of the copulation. During the second sampling period, the location of the uninvolved male during copulations was not systematically recorded. During both sampling periods, all observers were thoroughly trained, and high inter-observer reliability was verified, before the start of data collection.

\subsection{Data analyses}

Our data set included repeated measurements of the same male-female dyads, as well as measurements of the same male-female dyads under different sets of conditions (when transitions from unimale to two-male groups occurred). Therefore, we used Mixed Models in our analyses to examine the effect of a fixed factor (group type: unimale vs. two-male group) while including group identity as a random factor so as to control for the effect of random variation in sexual behavior among groups (or females, as the 
female group composition remained stable throughout the study). We compared copulation rates between males in unimale and multimale groups using Generalized Linear Mixed Models (GLMM) with group identity as a random factor, group type (unimale vs. two-male) as a fixed factor, and the number of copulations observed in each study month as a dependent variable. As the data involved counts within a specified period of time, we used a Poisson distribution with a Loglinear link function. Separate analyses were run comparing (i) all copulations involving the group female and (ii) only copulations involving the dominant male. For the analysis of copulation rates, all copulations of $\geqslant 2 \mathrm{~s}$ involving adult females were included, including copulations encountered while in progress, as long as the duration was known to be $\geqslant 2$ s. Copulations during the period of instability of group B in 2009 were excluded from all analyses. All other copulations that we observed were included in the analyses of copulation rates. On average, copulations by sexually active males were observed in about $30 \%$ of study months. Therefore, a sampling period spanning $>6$ months is required to have at least a $90 \%$ probability of observing a copulation by a given sexually active male. No copulations were observed in group $\mathrm{C}$ during the three-month period in which three males were present, and group $\mathrm{C} 2$ was observed in the two-male condition for a four-month period, during which only two copulations (by the same male) were observed. We did not classify mating within these multimale groups as polyandrous (i.e., at least two males mated) or monogamous (i.e., only the dominant male mated), as the small sample sizes made firm conclusions impossible. For group $\mathrm{C} 2$, copulation data in the two-male condition were included in analyses that considered the effects of the number of resident males in the group, but excluded from analyses that specifically focused on within-group mating patterns in multimale groups.

We compared the mean duration of copulations in the 2000-2002 and 2007-2009 sampling periods using Student's $t$-test for independent samples to exclude the possibility that differences between field teams introduced bias into the analyses. There was no difference in mean copulation duration between the 2000-2002 observation period (mean \pm SD $=47.2 \pm$ $42.0 \mathrm{~s}, N=67$ ) and the 2007-2009 observation period (mean $\pm \mathrm{SD}=$ $\left.47.6 \pm 39.2 \mathrm{~s}, N=91 ; t_{156}=-0.068, p=0.946\right)$. Copulation rates per focal hour were also approximately equal across the two sampling periods (0.0217 copulations/h in 2000-2002, 0.0222 copulations/h in 2007-2009), which suggests that there was not a substantial difference in detection rates 
between research teams. Thus, all data were grouped for subsequent analyses.

We compared the duration of copulations between males in unimale and multimale groups using Linear Mixed Models (LMM) with random and fixed factors as in the previous analysis, and duration of copulation (in seconds) as a dependent variable. Variables that were statistically redundant were removed from the final model. Copulations involving extra-group females $(N=2)$ and subadult females $(N=2)$ were excluded, as were copulations of unknown duration or of duration $\leqslant 2 \mathrm{~s}$. As some groups contained two sexually active males, separate analyses were run including (a) copulations by all males, and (b) copulations involving only the most frequently-copulating male (presumably the dominant male; Morino, 2012). We also compared the duration of copulations between males in the multimale groups where two males copulated using LMM with female/group identity as a random factor and male status (with the more-frequently-copulating male as Male 1 and the less-frequently-copulating male as Male 2) as a fixed factor and copulation duration as the dependent factor. We compared copulation durations in multimale groups where copulations are shared among males to the duration in multimale groups where a single male monopolizes copulations using LMM with group as a random factor and shared vs. monopolized copulations as a fixed factor. Analyses were conducted in IBM SPSS v. 20.

To test the prediction that copulations by males in two-male groups, especially subordinate males, occur more frequently when the uninvolved male is out of visual range of the copulating pair, we examined all data where the distance between the copulating pair and the uninvolved male was known, or where the uninvolved male was known to be $>20 \mathrm{~m}$ from the copulating pair. We chose $20 \mathrm{~m}$ as the boundary for visual detection in siamangs following the estimate of visual detection distances at Way Canguk by Lappan (2005) and Brockelman's (2009) study of visual detection distances at the canopy height in which hylobatids usually travel at Mo Singto in Thailand.

Siamangs copulate in trees, often high in the canopy, so observational conditions did not always permit us to conclusively determine whether ejaculation occurred, although ejaculation could sometimes be confirmed by visual detection of semen or observation of an ejaculatory pause. Thus, we were not able to determine whether copulation duration was related to probability of ejaculation in siamangs. 


\section{Results}

\subsection{Sampling}

A total of 185 copulations were observed, with duration data recorded for 167. Of these, 9 were very brief $(\leqslant 1 \mathrm{~s})$ in duration. Brief copulations occurred in unimale and two-male groups at similar rates $\left(t_{165}=0.733\right.$, $p=0.465$ ), and appeared to have been terminated prior to ejaculation. As the causes of rapid termination were unclear, these copulations were excluded from further analyses, leaving 158 copulations of known duration, of which 90 occurred in unimale groups, 63 occurred in two-male groups, and five occurred in an unstable group that included three males during a three-month transitional period.

\subsection{Copulation occurred more frequently in unimale than two-male groups}

Ten of the study groups contained two adult males for at least six consecutive months during a sampling period. In six of these cases, a single male was observed copulating with the group female. Nonetheless, the number of males in a group was a significant predictor of female monthly copulation rate $\left(F_{1,262}=18.836 ; p<0.001\right.$; Est. unimale group coefficient $=0.851$, $\mathrm{SE}=0.196)$ and dominant male-adult female copulation rate $\left(F_{1,89}=8.426\right.$, $p=0.005$; Est. unimale group coefficient $=0.758, \mathrm{SE}=0.261$ ). Females in unimale groups copulated at higher rates than females in two-male groups or dominant male-female dyads in two-male groups (Figure 1A, B).

\subsection{Copulations were significantly longer in unimale groups than in multimale groups}

In all analyses, the relationship between group type (unimale vs. twomale) and duration of copulation showed significant or near-significant $(p<0.10)$ variance in intercepts across females (all males: variance $=$ 252.37; $\chi_{1}^{2}=3.90, p=0.048$; only the most-frequently copulating male in each group: variance $=251.42 ; \chi_{1}^{2}=3.736, p=0.0533$ ), so female identity was included as a random factor. Copulations in unimale groups were significantly longer than those in multimale groups $\left(F_{1,92.5}=12.910\right.$, $p=0.001, t=-3.593, \beta=-26.84$; Figure $2 \mathrm{~A}$ ), even when only copulations by the dominant male-female pair were included $\left(F_{1,88.4}=9.662\right.$, $p=0.003, t=-3.108, \beta=-24.66$; Figure 2B). Copulations in group B2 in the period of instability during the replacement of the resident male were 

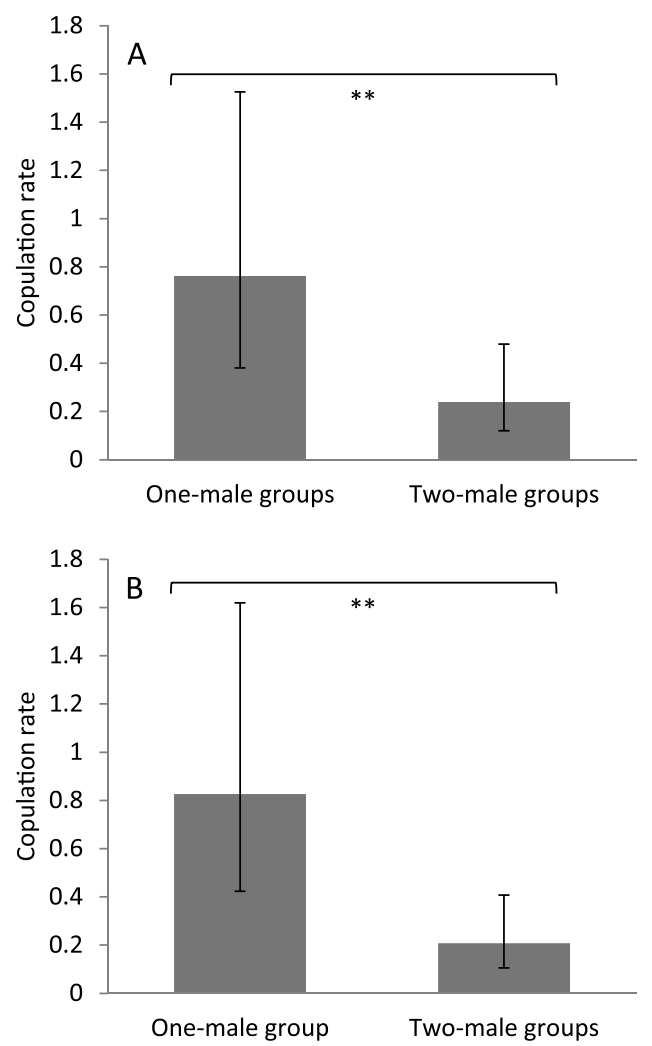

Figure 1. Comparison of estimated mean copulation rates (copulations/month) in unimale and multimale groups from the GLMM analyses. Error bars represent $95 \%$ confidence intervals of the estimated means. (A) All copulations involving the adult female and male group members. (B) Copulations involving dominant male-female dyads only. ${ }^{*} p<0.01$, ** $p<0.001$.

substantially shorter than those in stable unimale or stable multimale groups (Figure 2A, B).

3.4. Copulation duration did not differ between males in groups where two males copulated

In most two-male groups, only one male copulated with the group female. However, in three two-male groupings and in the transitional (three-male) grouping, two different males were observed copulating with the group female. In groups where two males copulated, the duration of copulations did not differ between the more-frequently copulating (and socially dominant; 

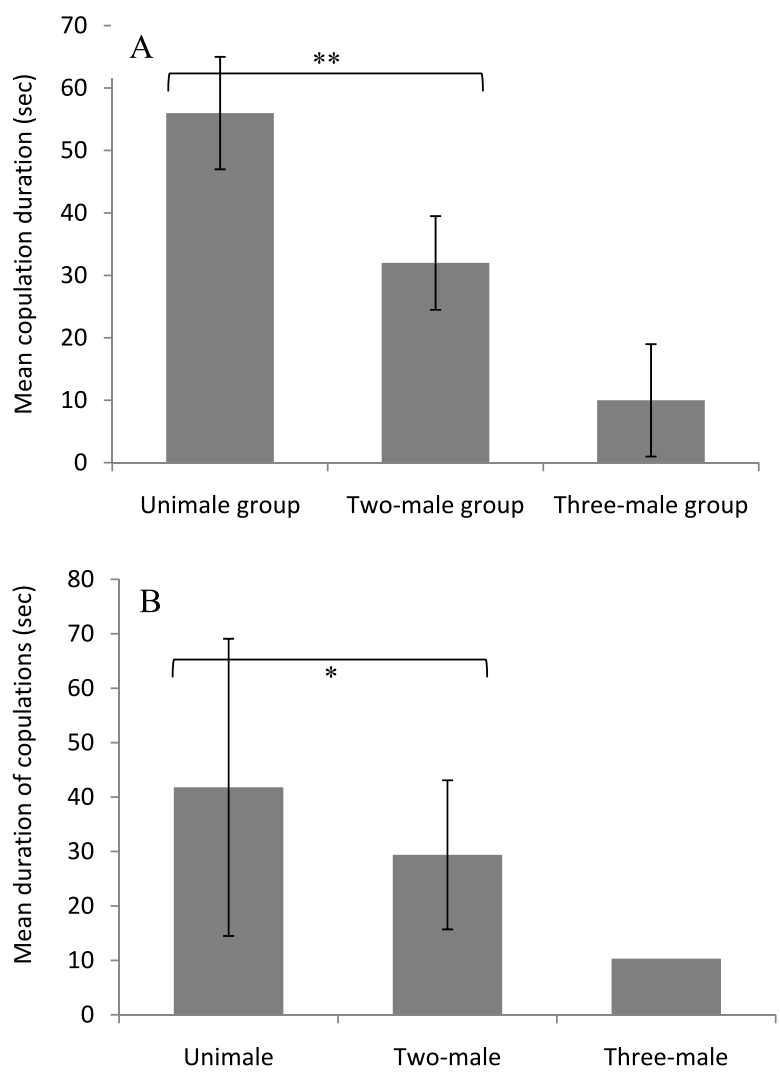

Figure 2. Mean duration of copulations by males in stable one-male groups and two-male groups, and an unstable three-male grouping. Means are calculated as means of group means. Error bars represent 95\% confidence intervals. (A) All copulations involving the adult female and male group members. (B) Copulations involving dominant male-female dyads only. The three-male group was not included in the LMM analysis. ${ }^{*} p<0.01,{ }^{* *} p<0.001$.

Morino, 2012) male and the less-frequently copulating (and thus presumably subordinate) male ( $F_{1,25}=0.045, p=0.834$; Table 2$)$.

3.5. Copulation duration and frequency in multimale groups did not differ when copulations were monopolized vs. shared among males

Copulations in groups where two males copulated did not differ significantly in duration $\left(F_{1,4.185}=0.513, p=0.512\right)$ or monthly frequency $\left(F_{1,52}=\right.$ 2.252, $p=0.105$ ) from those in multimale groups where a single male monopolized copulations (Figure 3). 
Table 2.

Copulation frequencies and durations for each dyad in multimale groups where both males copulated with the adult female.

\begin{tabular}{lllccc}
\hline Group & Time period & Dyad & Copulations & $\begin{array}{c}N \text { for } \\
\text { duration }\end{array}$ & $\begin{array}{c}\text { Duration } \\
\text { (mean } \pm \text { SD, s) }\end{array}$ \\
\hline A & Oct 2000-Dec 2001 & AF-AM1 & 3 & 3 & $28.3 \pm 40.4$ \\
& & AF-AM2 & 1 & 1 & 20.0 \\
B & Oct 2000-Aug 2002 & AF-AM1 & 13 & 11 & $27.3 \pm 25.1$ \\
& & AF-AM2 & 4 & 3 & $28.3 \pm 10.4$ \\
C & Oct 2000-Feb 2002 & AF-AM1 & 7 & 5 & $20.4 \pm 13.5$ \\
& & AF-AM2 & 6 & 4 & $21.3 \pm 10.3$ \\
B2 & Jan 2009-Mar 2009 & AF-AM1 & 1 & 1 & 5.0 \\
& & AF-Invader2 & 4 & 4 & $14.0 \pm 8.8$ \\
\hline
\end{tabular}

$N$ for duration $=$ number of copulations of known duration. $\mathrm{AF}=$ adult female. $\mathrm{AM} 1=$ Dominant male. AM2 = Subordinate male. Invader $2=$ formerly subordinate male who left the group for a few months, then returned and challenged and ultimately evicted the dominant male in group B.

${ }^{\mathrm{a}}$ There is some uncertainty about dominance relationships in group A.

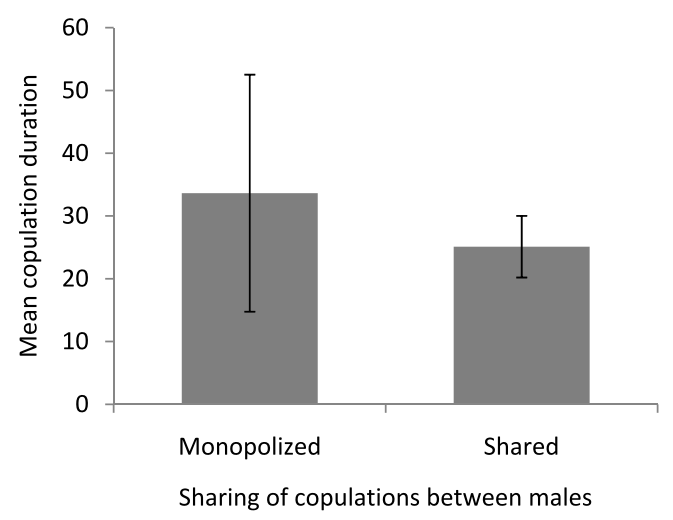

Figure 3. Mean duration of copulations in multimale groups where copulations were monopolized by the dominant male ('Monopolized') vs. groups where copulations were shared between two males ('Shared'). Means were calculated as means of individual means for all individuals for which at least two copulations were observed. Error bars represent $95 \%$ confidence intervals. ${ }^{*} p<0.01,{ }^{* *} p<0.001$. 
3.6. Copulations by dominant and subordinate males occurred $<20 \mathrm{~m}$ from the uninvolved males

In the 2000-2002 sampling period, the location of the second male was not determined during 20 out of 36 copulations involving the adult female. While this may indicate that second males were some distance from the observer (and therefore from the copulating pair), copulations were brief and occurred at unpredictable intervals, so in many cases the missing data resulted from the inability of the observers to quickly locate the second male while also verifying the identity of the copulating pair. Ten of the 16 copulations for which the location of the second male was known occurred $<20 \mathrm{~m}$ from the uninvolved male, including at least one copulation by each subordinate male in groups $\mathrm{A}, \mathrm{B}$ and $\mathrm{C}$.

\section{Discussion}

\subsection{Audience effects in multimale siamang groups and male social tolerance}

In accordance with our predictions, siamangs in two-male groups at Way Canguk copulated less frequently than siamangs in unimale groups (Figure 1) and their copulations were of shorter duration (Figure 2). Multiple variables, such as female reproductive condition (Beach, 1976), the interval between successive copulations (Dewsbury, 1972), food availability (Gill \& Rissman, 1997), and the history of social and sexual interactions among individuals (Hunter et al., 1993), are expected to affect animal sexual behavior. The emergence of clear differences in sexual behavior between unimale and multimale groups despite substantial within-dyad variation in copulation frequencies and durations and our inability to control for other potentially confounding variables, such as those mentioned above, suggests a fairly strong relationship between grouping pattern and sexual behavior in siamang groups. On several occasions, dominant or subordinate males that were residents of two-male groups became the lone males in unimale groups as a result of an emigration event or a takeover (Table 1; unpubl. data), which suggests that there is not a substantial difference in quality between males in unimale and two-male groups. The effect of grouping pattern on sexual behavior also remained when copulations by subordinate males were excluded. Thus, the differences in copulation rate and duration between unimale and 
two-male groups suggest an observer effect whereby adult pairs modify their sexual behavior in the presence of a second group male in ways that may reduce the risk of detection, harassment, or interruption of copulations. Male social tolerance in this species may be mediated by such individual behavioral responses to social or environmental conditions.

Our third prediction, that males in two-male groups, and particularly subordinate males, should preferentially copulate with group females in locations where detection by other males is unlikely, was not supported by our data. Over $30 \%$ (4 out of 11) of copulations by subordinate males are known to have occurred within $20 \mathrm{~m}$ of dominant males. It is possible that this reflects the small sample size for copulations by subordinate males. Alternatively, subordinate males may employ other strategies to avoid detection or aggression from dominants. For example, one copulation by a subordinate occurred during an inter-group encounter, when the dominant male was focused on the opposing group, and another such copulation occurred when the dominant male was nearby, but facing away from the copulating pair. Copulations such as these may be effectively cryptic despite the close spatial proximity of the dominant male. A third possibility is that copulations occurring in a location that could not be visually detected by the dominant male were also less likely to be detected by human observers, which may have resulted in observational bias. The fact that dominant males as well as subordinates copulated less frequently in multimale groups supports the interpretation that the differences observed in this study are real, and not just an artifact of observational bias, although bias against detection of brief and cryptic copulations undoubtedly occurred.

\subsection{Weaknesses and potential confounding variables}

Our results suggest that siamangs in multimale groups adjust their sexual behavior in a way that may minimize the risk of detection, harassment, or interruption by other adult male group members. Nonetheless, in $>5000 \mathrm{~h}$ of observations of multimale groups, we never observed male aggression directed at a copulating pair (although copulations were occasionally interrupted by infants or juveniles), even when copulations occurred $<20 \mathrm{~m}$ from the uninvolved male. There are at least two possible interpretations of this pattern. First, low rates of aggression may reflect the effectiveness of male strategies to reduce aggression risk and promote social tolerance in multimale siamang groups. Alternatively, the apparent relationship between 
grouping pattern and copulation characteristics may reflect relationships between these variables and a third variable. None of the females that were observed copulating with two different male group members conceived during the sampling period, and some copulations involved females that were pregnant or lactating. It is possible that dominant males are more tolerant of second males in their groups during periods when the group female is unlikely to conceive. The reduced frequency and shorter duration of copulation in multimale groups relative to unimale groups may thus reflect underlying relationships between female reproductive status and both variables. Further studies of siamang behavioral endocrinology will be necessary to understand the relationship between female cycle status, grouping pattern, and sexual behavior in this population.

\subsection{The effects of dominance rank on sexual behavior in two-male siamang groups}

Aggression among males within a group can be minimized through the establishment of a dominance hierarchy if subordinate males avoid contests with dominants. However, in three of the study groups, both males copulated with the group female. In the closely-related white-handed gibbon (Hylobates lar), subordinate males sire a small percentage (approx. 7\%) of offspring conceived in multimale groups (Barelli et al., 2013). Subordinate male gibbons may therefore be sexual competitors with dominant males despite the presence of a clear dominance hierarchy. Relatedness among adults may in some cases reduce the costs of within-group intrasexual competition. However, numerous observations of social 'sons' becoming pair-mates of their social 'mothers' in gibbon groups (Fuentes, 2000), including one of our study groups (Morino, 2012), coupled with genetic evidence that three of four subordinate males from the 2000-2002 sample were not the genetic offspring of the group female (Lappan, 2007a), caution against the assumption that subordinate males are the genetic offspring of dominant male-female pairs.

Aggression is usually directed by dominant males at subordinates. As a result, subordinates of many species display audience effects in the presence of dominants (e.g., chimpanzees: Townsend et al., 2008; bonobos: Clay \& Zuberbühler, 2012; rams: Lindsay et al., 1976; rhesus macaques: Manson, 1996; Overduin-de Vries et al., 2012), whereas there is less reason to expect an effect of subordinates on the behavior of dominants (Lindsay et al., 
1976; Ruiz de Elvira \& Herndon, 1986). In this study, though, an overall pattern of reduced copulation frequency and duration by dominant as well as subordinate males in two-male groups emerged. This result suggests that in multimale groups at Way Canguk the presence of subordinates affects the behavior of the dominant pair, whether the subordinate male copulates with the group female or not. Overduin-de Vries and colleagues (2012) also reported an effect of subordinate males on the behavior of copulating pairs in rhesus macaques (although the alpha male was not reported to be affected by the presence of non-alphas). These results show that audience effects may not always be unidirectional in animals living in complex social groups, and that closer attention should be paid to the effects of subordinates on the behavior of others. Another possibility is that the observed copulation pattern is driven by females, who should benefit from reduced male-male tension in the group.

\subsection{The significance of variation in copulation frequency and duration}

Frequent copulation may allow males to maximize reproductive success in the presence of sperm competition (Møller \& Birkhead, 1989). Thus, males in multimale groups are expected to copulate more frequently than males in unimale groups, a pattern which has been demonstrated across mammals (Møller \& Birkhead, 1989). However, in this study, males in two-male groups copulated less frequently than males in unimale groups (Figure 2). This result is consistent with our hypothesis that males in multimale groups adjust their sexual behavior to minimize the risk of aggression by other males. Copulation frequency and duration are determined by an interaction between male and female behavior. Copulatory behavior may be important in mate assessment (Hunter et al., 1993) and the formation and maintenance of pair bonds (Birkhead et al., 1987), and frequent mating may be a form of mate-guarding by females (Petrie, 1992). Thus, our results may actually reflect differences in female interests and male-female relationships in unimale and two-male groups. Females may affect the frequency of copulation through their rate or intensity of copulation solicitation (Janson, 1984; Davies et al., 1996) or via their responses to male copulation solicitations (Dickenson, 2001). Females can also terminate copulations or manipulate copulation duration through signals to the male. We observed females rejecting copulation attempts and terminating copulations in progress on several occasions. However, we were not able to examine other ways that females influence dyadic sexual interactions in the study population, or to attribute responsibility for the observed 
changes in sexual behavior in multimale groups to males or females or both. This is an important area for future investigation.

Longer copulations are associated with indicators of reproductive success, such as sperm transfer (Toner \& Adler, 1986; Edvardsson \& Canal, 2006; Pilastro et al., 2007), probability of ovulation (Adler, 1969; Erskine et al., 1989; deCatanzaro et al., 1991), and fertilization success (Himuro \& Fujisaki, 2012), in a number of animal species. Our results suggest that multimale grouping and male social tolerance affect sexual behavior in ways that are likely to impact the fitness of male and female group members. Quantification of these fitness consequences is an important area for future investigation.

\section{Acknowledgements}

Funding for S.L. was provided by the Leakey Foundation, Sigma Xi, the Fulbright Student Program, New York University, the Margaret and Herman Sokol Foundation and, during the writing stages, Appalachian State University. Funding for L.M. was provided by the National Science Foundation (Grant ID 0726022), the Wenner-Gren Foundation (Grant 7766), the Center for Human Evolutionary Studies and Rutgers University. We thank the Indonesian Institute of Sciences (LIPI) and the Indonesian Ministry of Research and Technology (RISTEK) for permission to conduct research in Indonesia, and the Indonesian Ministry of Forestry's Department for the Protection and Conservation of Nature (PHKA) for permission to conduct research in the Bukit Barisan Selatan National Park. The American-Indonesian Exchange foundation (AMINEF), Universitas Indonesia, and Wildlife Conservation Society-Indonesia Program provided considerable logistical support. Anton Nurcayho, Maya Dewi Prasetyaningrum, Mohammad Iqbal, Meyner Nusalawo, Teguh Priyanto, Tedy Presetya Utama, Janjiyanto, Sutarmin, Martin Trisunu Wibowo, Abdul Roshyd, Laji, Usman, Maryadi, Mislan and Budi provided essential assistance in the field. Erin Riley and two anonymous reviewers made many helpful suggestions that substantially improved this manuscript.

\section{References}

Adler, N.T. (1969). Effects of the male's copulatory behavior on successful pregnancy of the female rat. — J. Comp. Physiol. Psychol. 69: 613-622. 
Alberts, S., Altmann, J. \& Wilson, M.L. (1996). Mate guarding constrains foraging activity of male baboons. - Anim. Behav. 51: 1269-1277.

Altmann, J. (1974). Observational study of behavior: sampling methods. - Behaviour 49: 227-267.

Barelli, C., Matsudaira, K., Wolf, T., Roos, C., Heistermann, M., Hodges, K., Ishida, T., Malaivijitnond, S. \& Reichard, U.H. (2013). Extra-pair paternity confirmed in wild whitehanded gibbons. - Am. J. Primatol. 75: 1185-1195.

Beach, F.A. (1976). Sexual attractivity, proceptivity, and receptivity in female mammals. Horm. Behav. 7: 105-138.

Birkhead, T.R., Atkin, L. \& Møller, A.P. (1987). Copulation behavior in birds. — Behaviour 101: 101-138.

Brockelman, W.Y. (2009). Ecology and the social system of gibbons. — In: The gibbons: new perspectives on small ape socioecology and population biology (Lappan, S. \& Whittaker, D.J., eds). Springer, New York, NY, p. 211-240.

Bruce, K.E. \& Estep, D.Q. (1992). Interruption of and harrassment during copulation by stumptailed macaques, Macaca arctoides. — Anim. Behav. 44: 1029-1044.

Campbell, C. (2006). Copulation in free-ranging black-handed spider monkeys (Ateles geoffroyi). — Am. J. Primatol. 68: 507-511.

Cant, J. \& Johnstone, R.A. (2000). Power struggles, dominance testing, and reproductive skew. - Am. Nat. 155: 406-417.

Chapais, B. (1983). Reproductive activity in relation to male dominance and the likelihood of ovulation in rhesus monkeys. — Behav. Ecol. Sociobiol. 12: 215-228.

Chivers, D.J. (1974). The siamang in Malaya: a field study of a primate in tropical rain forest. - Karger, Basel.

Clay, Z. \& Zuberbühler, K. (2012). Communication during sex among female bonobos: effects of dominance, solicitation, and audience. - Sci. Rep. 2: 291.

Clutton-Brock, T.H. (1998). Reproductive skew, concessions and limited control. — Trends Ecol. Evol. 13: 288-292.

Davies, N.B., Hartley, I.R., Hatchwell, B.J. \& Langmore, N.E. (1996). Female control of copulations to maximize male help: a comparison of polygynandrous alpine accentors, Prunella collaris, and dunnocks, P. modularis. - Anim. Behav. 51: 27-47.

deCatanzaro, D., MacNiven, E. \& Rucciuti, F. (1991). Comparison of the adverse effects of adrenal and ovarian steroids on early pregnancy in mice. - Psychoneuroendocrinology 16: 525-536.

Dewsbury, D.A. (1972). Patterns of copulatory behavior in male mammals. - Q. Rev. Biol. 47: 1-33.

Dickenson, J.L. (2001). Extrapair copulations in western bluebirds (Sialia mexicana): female receptivity favors older males. - Behav. Ecol. Sociobiol. 50: 423-429.

Dubois, F. \& Belzile, A. (2012). Audience effect alters male mating preferences in zebra finches (Taeniopygia guttata). — PLoS ONE 7: e43697.

Edvardsson, M. \& Canal, D. (2006). The effects of copulation duration in the bruchid beetle Callosobruchus maculatus. — Behav. Ecol. 17: 430-434. 
Elder, A.A. (2013). Competition among three primate species at Way Canguk, Sumatra, Indonesia. - Unpubl. PhD thesis, Stony Brook University, Stony Brook, NY.

Erskine, M.S., Kornberg, E. \& Cherry, J.A. (1989). Paced copulation in rats: effects of intromission frequency and duration on luteal activation and estrous length. - Physiol. Behav. 45: 33-39.

Fuentes, A. (2000). Hylobatid communities: changing views on pair bonding and social organization in hominoids. - Yrbk. Phys. Anthropol. 43: 33-60.

Gill, C.J. \& Rissman, E.F. (1997). Female sexual behavior is inhibited by short- and long-term food restriction. - Physiol. Behav. 61: 387-394.

Himuro, C. \& Fujisaki, K. (2012). The effects of male harassment on mating duration in the seed bug, Togo hemipterus. - Endomol. Exp. Appl. 142: 53-59.

Hohmann, G. \& Fruth, B. (2003). Intra- and inter-sexual aggression by bonobos in the context of mating. - Behaviour 140: 1389-1413.

Hunter, F.M., Petrie, M., Otronen, M., Birkhead, T.R. \& Møller, A.P. (1993). Why do females copulate repeatedly with one male? - Trends Ecol. Evol. 8: 21-26.

Janson, C. (1984). Female choice and mating system of the brown capuchin monkey Cebus apella (Primates: Cebidae). — Z. Tierpsychol. 65: 177-200.

Kaburu, S.S.K., Inoue, S. \& Newton-Fisher, N.E. (2013). Death of the alpha: withincommunity lethal violence among chimpanzees of the Mahale Mountains National Park. — Am. J. Primatol. 75: 789-797.

Kinnaird, M.F. \& O'Brien, T.G. (1998). Ecological effects of wildfire on lowland rainforest in Sumatra. — Conserv. Biol. 12: 954-956.

Lappan, S. (2005). Biparental care and male reproductive strategies in siamangs (Symphalangus syndactylus) in southern Sumatra. — Dissertation, New York University, New York, NY.

Lappan, S. (2007a). Patterns of dispersal in Sumatran siamangs (Symphalangus syndactylus): preliminary mtDNA evidence suggests more frequent male than female dispersal to adjacent groups. — Am. J. Primatol. 69: 692-698.

Lappan, S. (2007b). Social relationships among males in multi-male siamang groups. — Int. J. Primatol. 28: 369-387.

Lindsay, D.R., Dunsmore, D.G., Williams, J.D. \& Syme, G.J. (1976). Audience effects on the mating behaviour of rams. - Anim. Behav. 24: 818-821.

Linklater, W.L. \& Cameron, E.Z. (2000). Tests for cooperative behavior between stallions. - Anim. Behav. 60: 731-734.

Manson, J.H. (1994). Male aggression: a cost to female mate choice in Cayo Santiago rhesus macaques. - Anim. Behav. 48: 473-475.

Manson, J.H. (1996). Male dominance and mount series duration in Cayo Santiago rhesus macaques. — Anim. Behav. 51: 1219-1231.

Marler, C.A. \& Moore, M.C. (1989). Time and energy costs of aggression in testosteroneimplanted free-living male mountain spiny lizards (Sceloporus jarrovi). — Physiol. Zool. 62: 1334-1350. 
Matos, R. \& Schlupp, I. (2005). Performing in front of an audience: signallers and the social environment. - In: Animal communication networks (McGregor, P.K., ed.). Cambridge University Press, Cambridge.

Matsumoto-Oda, A. (1999). Female choice in the opportunistic mating of wild chimpanzees (Pan troglodytes schweinfurthii) at Mahali. — Behav. Ecol. Sociobiol. 46: 258-266.

Mitani, J.C. (1984). The behavioral regulation of monogamy in gibbons (Hylobates muelleri). — Behav. Ecol. Sociobiol. 15: 225-229.

Mitani, J.C. (1987). Territoriality and monogamy among agile gibbons (Hylobates agilis). Behav. Ecol. Sociobiol. 20: 265-269.

Møller, A.P. \& Birkhead, T.R. (1989). Copulation behaviour in mammals: evidence that sperm competition is widespread. — Biol. J. Linn. Soc. 38: 119-131.

Morino, L. (2009). Monogamy in mammals: expanding the perspective on Hylobatid mating systems. - In: The gibbons: new perspectives on small ape socioecology and population biology (Lappan, S. \& Whittaker, D.J., eds). Springer, New York, NY, p. 279-312.

Morino, L. (2012). Behavioral endocrinology of wild male siamangs (Symphalangus syndactylus). - Unpubl. PhD thesis, Rutgers University, New Brunswick, NJ.

Mumme, R.L., Koenig, W.D. \& Pitelka, F.A. (1983). Mate guarding in the Acorn Woodpecker: within-group reproductive competition in a cooperative breeder. - Anim. Behav. 31: 1094-1106.

Nakamura, M. (1998). Multiple mating and cooperative breeding in polygynandrous alpine accentors I. Competition among females. - Anim. Behav. 56: 259-275.

Nicholson, A.J. (1954). An outline of the dynamics of animal populations. - Aust. J. Zool. 2: 9-65.

Nurcahyo, A. (1999). Studi perilaku harian siamang (Hylobates syndactylus) di taman nasional Bukit Barisan Selatan, Lampung. - Unpubl. BSc thesis, Universitas Gadjah Mada, Yogyakarta.

O'Brien, T.G., Kinnaird, M.F., Anton, N., Prasetyaningrum, M.D.P. \& Iqbal, M. (2003). Fire, demography and the persistence of siamang (Symphalangus syndactylus: Hylobatidae) in a Sumatran rainforest. - Anim. Conserv. 6: 115-121.

Overduin-de Vries, A.M., Maassen, J.J.M., Spruijt, B.M. \& Sterck, E.H.M. (2012). Sneaky monkeys: an audience effect of male rhesus macaques (Macaca mulatta) on sexual behavior. - Am. J. Primatol. 74: 217-228.

Padur, L., Wedekind, J., Öztürk, O., Streit, B., Tiedemann, R. \& Plath, M. (2009). Do audience effects lead to relaxed male sexual harassment? - Behaviour 146: 1739-1758.

Palombit, R.A. (1993). Lethal territorial aggression in a monogamous primate. - Am. J. Primatol. 31: 311-318.

Palombit, R.A. (1994). Dynamic pair bonds in hylobatids: implications regarding monogamous social systems. - Behaviour 128: 65-101.

Parker, G.A. (1974). Courtship persistence and female guarding as male time investment strategies. - Behaviour 48: 157-184.

Petrie, M. (1992). Copulation frequency in birds: why do females copulate more than once with the same male. — Anim. Behav. 44: 790-792. 
Pilastro, A., Mandelli, M., Gasparini, C., Dadda, M. \& Bisazza, A. (2007). Copulation duration, insemination efficiency and male attractiveness in guppies. - Anim. Behav. 74: 321-328.

Raemaekers, J.J. \& Raemaekers, P.M. (1985). Field playback of loud calls to gibbons (Hylobates lar): territorial, sex-specific and species-specific responses. - Anim. Behav. 33: 481-493.

Ruiz de Elvira, M. \& Herndon, J.G. (1986). Disruption of sexual behaviour by high ranking rhesus monkeys (Macaca mulatta). - Behaviour 96: 227-240.

Sapolsky, R.M. (2005). The influence of social hierarchy on primate health. - Science 308: 648-652.

Silk, J.B. (2002). Kin selection in primate groups. — Int. J. Primatol. 23: 849-875.

Toner, J.P. \& Adler, N.T. (1986). The pre-ejaculatory behavior of male and female rats affects the number of sperm in the vagina and uterus. - Physiol. Behav. 36: 363-367.

Townsend, C.R., Deschner, T. \& Zuberbühler, K. (2008). Female chimpanzees use copulation calls flexibly to prevent social competition. - PLoS ONE 3, DOI:10.1371/journal. pone.0002431.

Townsend, C.R. \& Zuberbühler, K. (2009). Audience effects in chimpanzee copulation calls. — Common Integr. Biol. 2: 282-289.

Watts, D.P. (1998). Coalitionary mate guarding by male chimpanzees at Ngogo, Kibale National Park, Uganda. — Behav. Ecol. Sociobiol. 44: 43-55. 